\title{
Low-Complexity Full-Melt Laser-Anneal Process for Fabrication of Low-Leakage Implanted Ultrashallow Junctions
}

\author{
CLEBER BIASOTTO,${ }^{1,4}$ VIKTOR GONDA, ${ }^{1,2}$ LIS K. NANVER, ${ }^{1}$ \\ TOM L.M. SCHOLTES, ${ }^{1}$, JOHAN VAN DER CINGEL, ${ }^{1}$ DANIEL VIDAL, ${ }^{1}$ \\ VLADIMIR JOVANOVIĆ ${ }^{1,3,5}$

\begin{abstract}
1.-Delft Institute of Microsystems and Nanotechnology DIMES, Delft University of Technology, Feldmannweg 17, 2628 CT Delft, The Netherlands. 2.-Present address: Institute of Mechanical and Materials Engineering, College of Dunaújváros, Táncsics M. u. 1/a, Dunaújváros 24000, Hungary. 3.-Faculty of Electrical Engineering and Computing, University of Zagreb, Unska 3, 10000 Zagreb, Croatia. 4.—e-mail: c.biasotto@tudelft.nl. 5.—e-mail: v.jovanovic@tudelft.nl
\end{abstract}

\begin{abstract}
Good-quality ultrashallow $n^{+} p$ junctions are formed using 5-keV amorphizing $\mathrm{As}^{+}$implantations followed by a single-shot excimer laser anneal for dopant activation. By using an implant that is self-aligned to the contact windows etched in an oxide isolation layer, straightforward processing of the diodes is achieved with postimplantation processing temperatures kept below $400^{\circ} \mathrm{C}$. A possible source of junction leakage at the perimeter caused by dip-etch enlargement of the contact window, also confirmed by transmission electron microscopy (TEM) analysis, is identified, and diode performance is improved by increasing the junction/contact window overlap. The optimum performance in terms of low leakage, shallow junctions, and low resistivity is achieved for $30^{\circ}$ tilted implants and by applying a thin laser-reflective aluminum layer. This work isolates the minimum requirements for achieving low-leakage diode characteristics.
\end{abstract}

Key words: Excimer laser annealing, ultrashallow junctions, tilted implantations, low-temperature processing, reflective masking layer

\section{INTRODUCTION}

Laser annealing for implanted dopant activation has been receiving considerable attention since it was put on the International Technology Roadmap for Semiconductors (ITRS) in 1999 as one of the only means of achieving the targets for source/drain requirements related to the scaling down of complementary metal-oxide-semiconductor (CMOS) devices in silicon. ${ }^{1}$ Many experiments based on doping profiling and sheet resistance measurements have shown that both full-melt and laser thermal processing can result in attractive values for junction depth, abruptness, and sheet resistance. ${ }^{2-8}$ Of the rapid anneal procedures investigated for future CMOS devices, excimer laser annealing (ELA) has

(Received January 28, 2011; accepted August 9, 2011;

published online September 9, 2011) the shortest annealing times, practically eliminating any transient-enhanced diffusion (TED) effects, and also offers benefits such as precise control of junction depth, good abruptness of the dopant profile, and high dopant activation. The depth of junctions processed by full-melt ELA can be precisely controlled by applying amorphizing ion implantation, since amorphous silicon has a lower melting temperature than crystalline silicon, and the energy density of the laser light can be adjusted to only melt the top amorphous region, thus aligning the junction depth to the amorphous/crystalline interface region. ${ }^{9-13}$ Therefore, for this type of annealing a reduction of the vertical implantation range can serve as a direct means of also decreasing the junction depth.

The laser processing research presented in this paper, rather than being aimed at the fabrication of source and drain regions for CMOS, has been 
motivated by the need to have access to good-quality diodes in integration situations where only very low temperatures are permitted. This is, for example, the case when adding sensor/actuator elements to fully processed CMOS wafers and in the post-substrate-transfer processing of silicon-on-glass devices. ${ }^{14}$ In the former case the metallization will limit the further processing to the $400^{\circ} \mathrm{C}$ to $500^{\circ} \mathrm{C}$ range, and in the latter case the adhesive used for substrate transfer will force the limit even further down to $300^{\circ} \mathrm{C}$. With the full-melt high-power ELA that is the topic of this paper, essentially roomtemperature annealing can be achieved because the laser energy only heats an ultrashallow surface region and the silicon substrate serves as a heat sink, resulting in a large temperature gradient and virtually no heating outside the irradiated surface region. Moreover, for the targeted applications, low complexity is an important requirement, since they often involve large-area structures (e.g., photodiodes, protection diodes, passive elements) that cannot profit from aggressive downscaling to become cost-effective. This paper presents the most straightforward and therefore most widely applicable processing scheme that has issued from our research towards such low-cost add-on diodes. In this process the dopants are implanted in a contact window etched through a layer stack of $\mathrm{Al}$ (the reflective mask for the laser annealing) on a $\mathrm{SiO}_{2}$ surface isolation layer. Full-melt laser annealing is then performed, and the resulting diode is metallized without any further thermal processing. In this way the diode is self-aligned to the original contact window. This paper discusses in detail the intricacies of each stage of this fabrication process, and on the basis of these observations, general conclusions are made on the conditions that are important for achieving good-quality diodes also in situations where downscaling will demand more complex overall processing; for example, a variant of the process was adopted in the fabrication of lowtemperature metal-gate $n$-channel devices as described in Refs. 15 and 16.

\section{EXPERIMENTAL PROCEDURES}

The starting material is $2 \Omega \mathrm{cm}$ to $5 \Omega \mathrm{cm}$ (100) $p$-type silicon wafers, which are processed with $n^{+}$ buried layers and both deep and shallow implants so that the fabricated diode is embedded in a surface layer doping of $10^{17} \mathrm{~cm}^{-3}$ and can be contacted from the front of the wafer with low series resistance. Silicon dioxide is used as surface passivation and isolation layer for the diodes. Of the various possible ways to grow or deposit an oxide layer on the silicon surface, thermal oxidation gives the highest-quality layer in terms of defect-state density at the interface to silicon and the density of the oxide itself. Hence, the etch rate of thermal oxide during a typical dipetch step to remove native oxide is low. In our case only $10 \mathrm{~nm}$ is removed during a 4-min dip in $0.55 \%$ hydrofluoric acid (HF) solution, which is attractive for control of the lateral dimensions. Oxide layers deposited by low-pressure chemical vapor deposition (LPCVD) and plasma-enhanced chemical vapor deposition (PECVD) have inferior interface properties and etch significantly faster in HF. On the other hand, they can be deposited at much lower temperatures than normally usable for thermal oxidation. The experiments presented here in detail make use of a 330-nm-thick oxide stack consisting of a 30 -nm-thick thermal oxide grown at $850^{\circ} \mathrm{C}$, which gives a good interface to the silicon, covered with a 300-nm-thick LPCVD oxide deposited at $700^{\circ} \mathrm{C}$ from tetraethyl orthosilicate (TEOS) source, which reduces the total thermal budget. A layer of 100-nmthick aluminum with $1 \%$ silicon $[\mathrm{Al} / \mathrm{Si}(1 \%)]$ is then deposited by physical vapor deposition (PVD) to serve as a reflective masking layer for the laser light, as shown in Fig. 1. Aluminum has been shown to be efficient in protecting regions that should not be modified during laser annealing., ${ }^{6,8}$ The low implantation energy required for fabricating shallow junctions also makes the implantation profile very dependent on the state of the silicon surface prior to ion implantation. It has been demonstrated that a clean and smooth surface is essential for having good electrical characteristics of the implanted junctions annealed by ELA, which requires soft landing during reactive-ion etching (RIE) steps and native oxide removal before implanting ions. ${ }^{17}$ Various HF solutions can be used for the stripping of native oxide, the applicability of which will depend on the degree to which other layers are etched.

Openings in the isolating/reflective stack are patterned in resist and etched by first reactive-ion etching of $\mathrm{Al} / \mathrm{Si}(1 \%)$ using hydrogen bromide and chlorine plasma and then oxide RIE using a fluorine-based plasma. To prevent damage to the silicon surface from the RIE process, the removal of the last part of the oxide isolation is done at lower radiofrequency (RF) power of $100 \mathrm{~W}$, compared with $300 \mathrm{~W}$ during bulk oxide etching. As specified in Table I, soft landing on the silicon surface results in smaller surface roughness, as good as that achieved by wet landing using HF solutions, but with the advantage of not significantly etching in the lateral direction. ${ }^{17,18}$ Native oxide is removed in buffered HF (BHF) diluted with water in 1:7 ratio during a 15-s dip that is performed immediately prior to the implantation of $\mathrm{As}^{+}$ions. Aluminum is readily etched by HF solutions, but a dip in $\operatorname{BHF}(1: 7)$ is preferable here because the $\mathrm{Al}$ etching saturates after approximately $50 \mathrm{~nm}$, leaving a sufficiently thick $\mathrm{Al} / \mathrm{Si}(1 \%)$ layer to function as a reflective mask. However, any etching of the $\mathrm{Al} / \mathrm{Si}(1 \%)$ layer creates a rough surface that degrades the reflectivity. To prevent this, the $\mathrm{Al}$ around the contact windows is protected by resist during dip-etching and implantation. The resist used to pattern the windows themselves cannot be used for this purpose because resist at the window perimeter will then be 
(a)

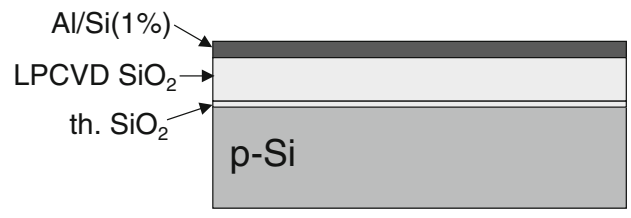

(b)

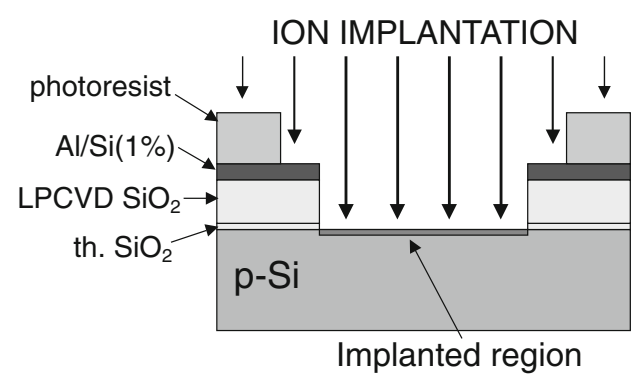

(c)

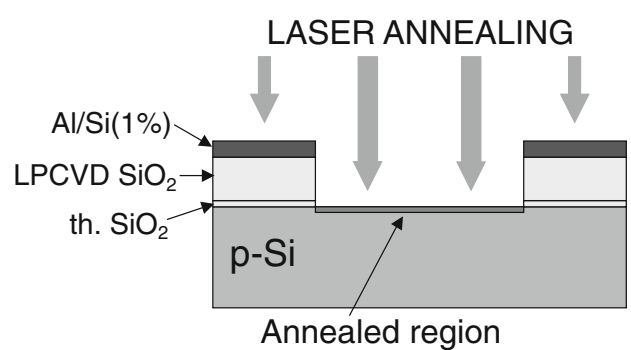

(d)

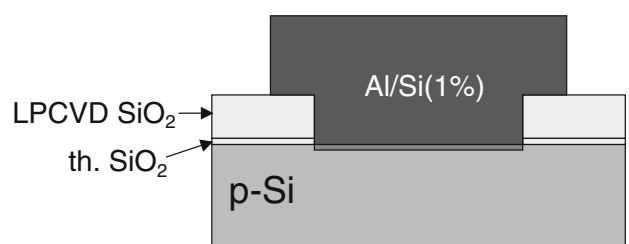

Thermal oxidation $-30 \mathrm{~nm}$

LPCVD oxide $-300 \mathrm{~nm}$

$\mathrm{Al} / \mathrm{Si}(1 \%)-100 \mathrm{~nm}(\mathrm{a})$

Lithography - contact opening

Contact hole etching by RIE

Lithography - enlarged contact

$\operatorname{BHF}(1: 7), 15 \mathrm{~s}$

$\mathrm{As}^{+}$implantation (b)

ELA (c)

$\mathrm{HF}(0.55 \%), 4 \mathrm{~min}$

$\mathrm{Al} / \mathrm{Si}(1 \%)-675 \mathrm{~nm}$

Metallization patterning by RIE

Alloying @ $400^{\circ} \mathrm{C}, 30$ min (d)

Fig. 1. Schematic process flow for fabrication of $\mathrm{As}^{+}$-implanted and laser-annealed ultrashallow $n^{+} p$ diodes.

Table I. Pre-implantation root-mean-square (RMS) surface roughness as a function of the type of reflective mask and etch process used for landing on silicon ${ }^{18}$

\begin{tabular}{|c|c|c|}
\hline Type of Landing & Al (̊̊) & $\mathbf{A l} / \mathbf{S i}(1 \%)(\AA)$ \\
\hline Hard, $300 \mathrm{~W}$ & 17 & 27 \\
\hline Soft, $100 \mathrm{~W}$ & 12 & 12 \\
\hline Wet, $\operatorname{BHF}(1: 7)$ & 11 & 35 \\
\hline
\end{tabular}

co-implanted in the openings to the silicon and this degrades the ideality of the final laser-annealed junction. Therefore, an additional lithography step is applied where the contact-window mask is oversized by $0.3 \mu \mathrm{m}$ to $0.5 \mu \mathrm{m}$. The $\mathrm{As}^{+}$ions are implanted with an energy of $5 \mathrm{keV}$ and to a dose of either $10^{15} \mathrm{~cm}^{-2}, 2 \times 10^{15} \mathrm{~cm}^{-2}$ or $3 \times 10^{15} \mathrm{~cm}^{-2}$. To reduce the vertical implantation range, ions are implanted at angles of either $7^{\circ}, 30^{\circ}$ or $45^{\circ}$. Moreover, the higher tilt angles will result in some dopants being implanted further underneath the isolation oxide, thereby increasing the overlap between the isolation oxide and the junction. During the implantation, some $\mathrm{Al}$ atoms can be knocked from the top layer and predominantly sputtered in the direction of the $\mathrm{As}^{+}$ions. However, during a dip in $\mathrm{BHF}(1: 7)$ the $\mathrm{Al}$ is recessed approximately $50 \mathrm{~nm}$ more than the LPCVD oxide since it is exposed to the solution also from the bottom side. The recess of $\mathrm{Al}$ is sufficient to prevent it from being sputtered onto the contact window for all the implantation angles used in our experiments, as has been indicated in Fig. 2.

Laser annealing was performed using an Exitech M800V double laser system with a Lambda Physik LPX $210 \mathrm{XeCl}$ excimer laser with a wavelength of $308 \mathrm{~nm}$ and a pulse duration of $25 \mathrm{~ns}$ full-width at half-maximum (FWHM) using single-shot illumination. A flat-top intensity profile was produced over a $1.75 \mathrm{~mm} \times 2.5 \mathrm{~mm}$ spot by using a homogenizer, and energy densities of laser illumination were varied from $700 \mathrm{~mJ} / \mathrm{cm}^{2}$ to $1000 \mathrm{~mJ} / \mathrm{cm}^{2}$. Sputtering of $\mathrm{Al} / \mathrm{Si}(1 \%)$ is used for contacting of the diodes, preceded by a dip-etch in HF $(0.55 \%)$ for $4 \mathrm{~min}$ to remove native oxide, passivate the surface with hydrogen, and ensure reliably low contact resistance. When necessary, an additional substrate contact is also created on the backside of the wafer. The processing ends with alloying in forming gas for 
RIE with "soft landing"

(a)

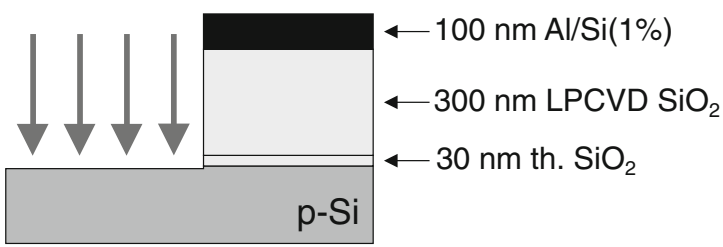

(b)
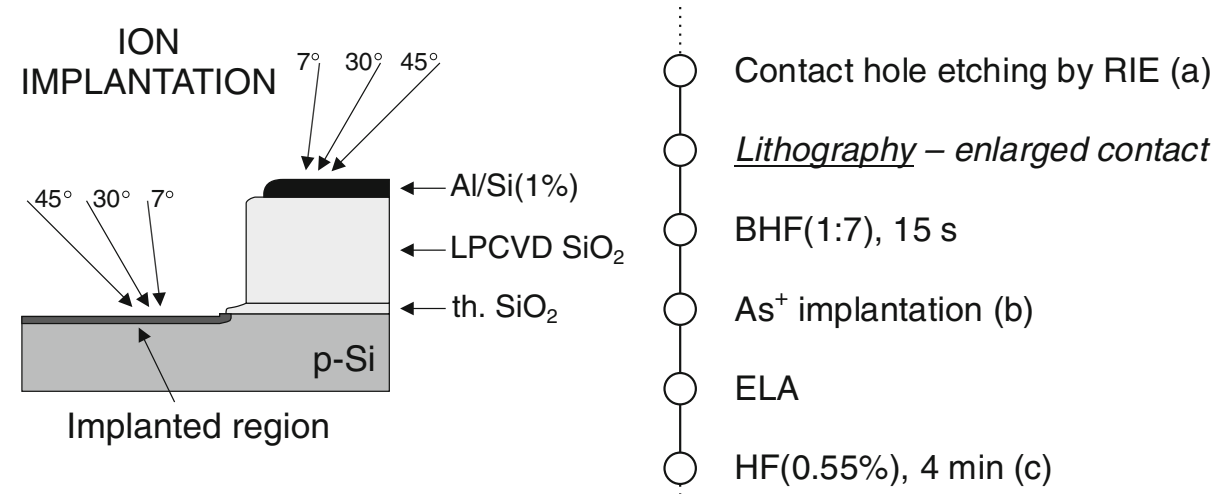

(c)

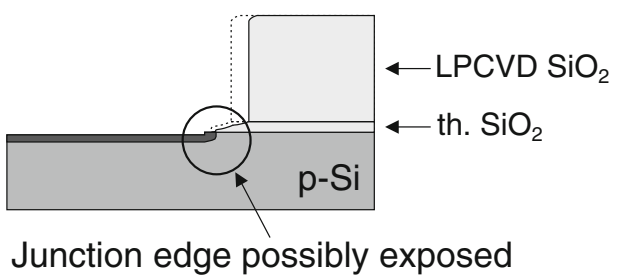

Fig. 2. Transformation of the structure of the contact window perimeter as it undergoes (a) oxide RIE, (b) pre-implantation native oxide removal in $\mathrm{BHF}(1: 7)$, and (c) premetallization stripping of the native oxide in HF $(0.55 \%)$. The schematic is drawn to scale and assumes an ideally vertical etching profile as obtained by RIE.

20 min at $400^{\circ} \mathrm{C}$, which is the highest-temperature step after the deposition of the LPCVD oxide layer.

\section{STRUCTURAL JUNCTION PROPERTIES}

\section{Junction Morphology}

The processing steps which predominantly determine the surface properties of the ultrashallow junctions and the position and shape of the contact opening perimeter are: (i) RIE of the isolation oxide stack, (ii) native oxide removal in $\mathrm{BHF}(1: 7)$ prior to ion implantation, (iii) ion implantation, (iv) excimer laser annealing of the structure, and (v) native oxide removal in $\mathrm{HF}(0.55 \%)$ before metallization. An overview of the transformations of the contact perimeter at each of these stages is depicted in Fig. 2. The selectivity of the oxide RIE in the fluorine-based plasma system to silicon is approximately $10: 1$, but a certain overetch time is included to remove all oxide inside the opening before junction implantation, albeit at lower RF power. Native oxide removal by surface treatment by $\mathrm{BHF}(1: 7)$ for $15 \mathrm{~s}$ immediately prior to the $\mathrm{As}^{+}$implantation also etches the isolation oxide in the lateral direction. The LPCVD oxide is removed faster than the thermal oxide, giving a recess of about $60 \mathrm{~nm}$ in addition to the $8 \mathrm{~nm}$ to $9 \mathrm{~nm}$ removed near the interface.
The slow etch rate of the thermal oxide is beneficial if maintaining minimum contact window size is important since tight control over the junction dimensions is then preserved after this step, but otherwise the type of oxide used at the interface is not critical at this stage of the process. The subsequent high-dose ion implantation amorphizes the surface region of the silicon substrate and also sputters some of the silicon atoms from the surface, an effect that increases with tilt angle: with a tilt angle of either $7^{\circ}, 30^{\circ}$ or $45^{\circ}$, respectively, $1,1.58$ or $6 \mathrm{Si}$ atoms are removed per $\mathrm{As}^{+}$ion. ${ }^{18}$ In general, illumination by laser light melts the exposed surface layer to a depth that depends on the laser energy, but also on the depth of the region amorphized by ion implantation because the amorphous silicon has a lower melting temperature than the crystalline silicon. ${ }^{9}$ The optimum annealing is achieved if the laser energy is tuned to melt the complete amorphous region which recrystallizes epitaxially from the underlying crystalline substrate. The absorption length of light with $308 \mathrm{~nm}$ wavelength is less than $10 \mathrm{~nm}$ in silicon, in both the solid and liquid phase, and the major part of the laser energy is absorbed at the Si surface. Additionally, the heat-sinking capability of the silicon substrate keeps the region beyond a few microns from the irradiated area 
effectively at room temperature, whereas the lower melting temperature of the amorphous silicon ensures that only this region melts during laser action. ${ }^{10-13}$ The melt onset begins at $600 \mathrm{~mJ} / \mathrm{cm}^{2}$, and full melt to a depth of $20 \mathrm{~nm}$ happens for $1100 \mathrm{~mJ} / \mathrm{cm}^{2} .{ }^{18}$ However, for energy densities above $1000 \mathrm{~mJ} / \mathrm{cm}^{2}$, surface degradation patterns can develop that are referred to as laser-induced periodic surface structuring (LIPSS). Such surface degradation can have a large impact on the quality of an ultrashallow junction, and the maximum laser energy density was therefore limited to $1000 \mathrm{~mJ} /$ $\mathrm{cm}^{2}{ }^{19}$ The high temperature achieved in the melted region decays toward the bulk of the wafer and in the lateral direction, but it can also exceed ablation limits of the aluminum layer used as the reflective mask, in which case some of the $\mathrm{Al} / \mathrm{Si}(1 \%)$ is removed from the edges of the openings while the oxide isolation remains unchanged. This is shown in Fig. 3 for contact windows which were opened through the stack of oxide and reflective $\mathrm{Al} / \mathrm{Si}(1 \%)$ layers, implanted, and laser annealed. A small part of the laser light is absorbed in the $\mathrm{Al} / \mathrm{Si}(1 \%)$ and is not conducted away efficiently due to the low thermal conductance of the thick underlying oxide. This causes ablation of $\mathrm{Al} / \mathrm{Si}(1 \%)$ at the edges that increases with laser energy density. ${ }^{17}$ The premetallization HF dip-etch further etches the oxide layers, and this step can potentially expose the junction edges as indicated in Fig. 2c. For this reason it becomes attractive to use implantations at higher tilt angles to increase the lateral junction extension under the sides. In Fig. 4, a TEM image of the final contact opening confirms the shape of the edge of the isolation layer, with only a small lateral removal of the thermal oxide layer as opposed to the LPCVD oxide. A slight loss of silicon at the surface in the implanted region can also be observed. This may stem from the overetch during oxide RIE, Si sputtering during implantation, and/or native oxide removal.

\section{Doping Profiles}

Secondary-ion mass spectrometry (SIMS) analyses of the samples implanted with arsenic ions to a dose of $10^{15} \mathrm{~cm}^{-2}$ at different tilt angles and laser annealed at $1000 \mathrm{~mJ} / \mathrm{cm}^{2}$ are shown in Fig. 5. The main parameters extracted from these profiles are listed in Table II. The increase in tilt angle results

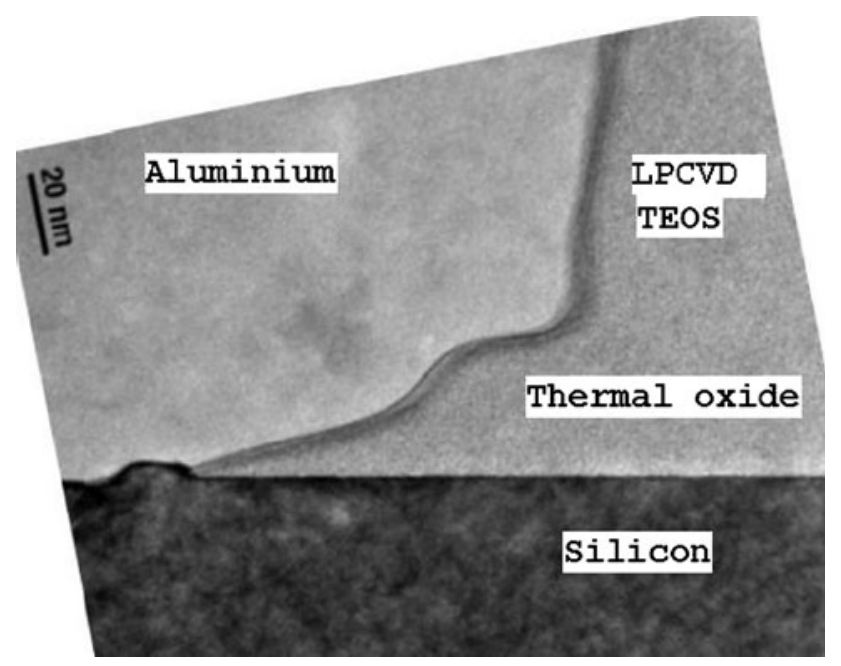

Fig. 4. TEM image of the edge of a contact window that has been exposed to steps $(\mathrm{a}-\mathrm{c})$ illustrated in Fig. 2.

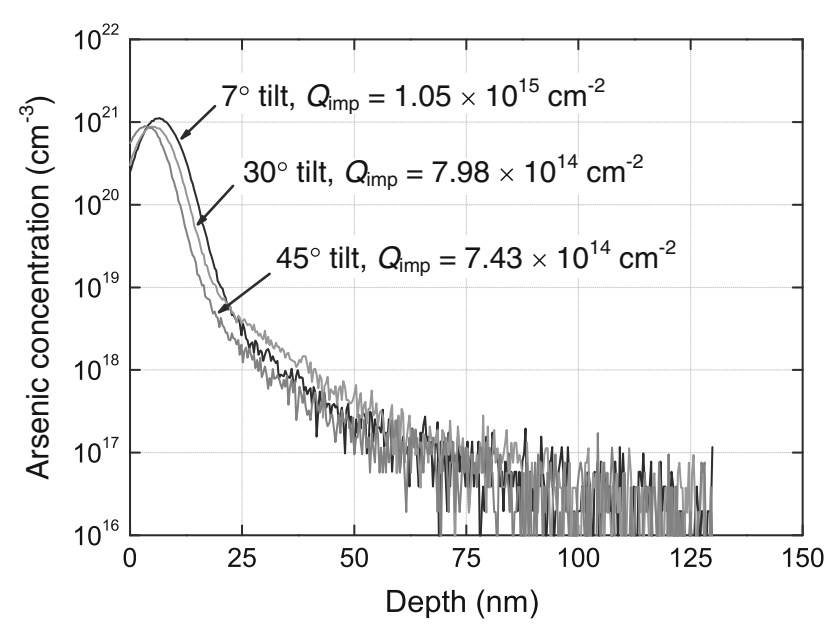

Fig. 5. SIMS profiles of 5-keV As implants to dose of $10^{15} \mathrm{~cm}^{-2}$ at tilt angles of $7^{\circ}, 30^{\circ}$, and $45^{\circ}$, laser annealed at $1000 \mathrm{~mJ} / \mathrm{cm}^{2}$. The dose $Q_{\mathrm{imp}}$ extracted by integration of the respective profile is indicated.

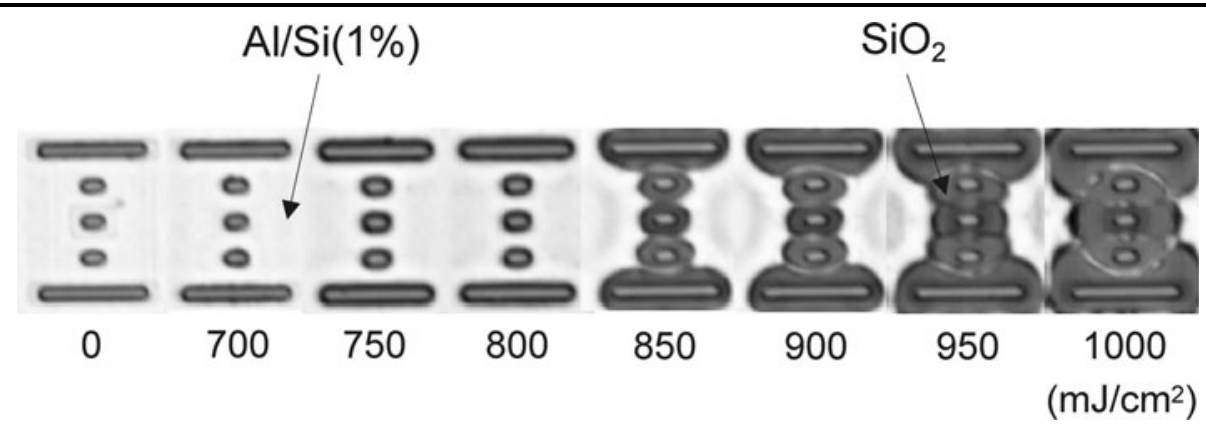

Fig. 3. Series of microphotographs of five implanted and laser-annealed contact windows as a function of laser energy from $0 \mathrm{~mJ} / \mathrm{cm}^{2}$ to $1000 \mathrm{~mJ} / \mathrm{cm}^{2}$. The light-grey area is the reflective Al masking layer, the middle grey is the $\mathrm{Si}$ of the contact window, and the dark grey is $\mathrm{SiO}{ }_{2}$ around the contact window that is exposed due to ablation of the Al layer during the illumination by laser light. 
Table II. Summary of junction properties after implantation and laser annealing at $1000 \mathrm{~mJ} / \mathrm{cm}^{2}$

\begin{tabular}{|c|c|c|c|c|c|}
\hline $\begin{array}{l}\text { Laser Energy } \\
\text { Density }\left(\mathrm{mJ} / \mathrm{cm}^{2}\right)\end{array}$ & $\begin{array}{c}\text { Nominal } \\
\text { Dose }\left(\mathrm{cm}^{-2}\right)\end{array}$ & $\begin{array}{c}\text { Implantation } \\
\text { (Tilt Angle) }\end{array}$ & $\begin{array}{l}\text { Implantation Dose, } \\
\text { SIMS }\left(\mathrm{cm}^{-2}\right)\end{array}$ & $\begin{array}{l}\text { Junction } \\
\text { Depth (nm) }\end{array}$ & $\begin{array}{l}\text { Sheet Resistance } \\
\text { Avg. }(\Omega / \text { square })\end{array}$ \\
\hline 1000 & $1 \times 10^{15}$ & $7^{\circ}$ & $1.05 \times 10^{15}$ & 20 & 220 \\
\hline 1000 & $1 \times 10^{15}$ & $30^{\circ}$ & $7.98 \times 10^{14}$ & 18 & 275 \\
\hline 1000 & $1 \times 10^{15}$ & $45^{\circ}$ & $7.43 \times 10^{14}$ & 15 & 311 \\
\hline
\end{tabular}

in shallower doping profiles, from $20 \mathrm{~nm}$ at $7^{\circ}$ tilt down to only $15 \mathrm{~nm}$ at $45^{\circ}$, with a small amount of channeling being observed for the tilt of $30^{\circ}$. However, with higher tilting of the ion beam, a lower effective dose is implanted since the area exposed to the ion beam is proportional to the cosine of the tilt angle. This is further exacerbated with more ions reflected from the silicon surface at the higher tilt, resulting in the measured implanted doses of $1.05 \times 10^{15} \mathrm{~cm}^{-2}, \quad 7.98 \times 10^{14} \mathrm{~cm}^{-2}$, and $7.43 \times$ $10^{14} \mathrm{~cm}^{-2}$ at tilt angles of $7^{\circ}, 30^{\circ}$, and $45^{\circ}$ respectively, for the same ion dose generated by the implanter. To compensate for this effect, a higher ion dose setting could be used as the tilt angle is increased. The practical limit for the reduction of junction depth using the increase in implantation tilt depends on the size of the contact opening, since more shadowing of the implanted ions by the thermal oxide/LPCVD oxide/aluminum stack will occur at larger angles. This effect has more impact as the lateral dimensions are scaled down. Furthermore, the increased surface roughness from LIPSS at higher annealing energies can start to play a more significant role and increase the leakage when the junction depth reaches a critically low value.

\section{ELECTRICAL CHARACTERIZATION}

\section{Current-Voltage Characteristics}

The quality of the ultrashallow $n^{+} p$ junctions was evaluated by examining the reverse leakage current and the ideality of the forward current-voltage characteristics. The $\mathrm{I}-V$ characteristics of the $\mathrm{As}^{+}-$ implanted diodes laser-annealed with an energy density of $1000 \mathrm{~mJ} / \mathrm{cm}^{2}$ are shown in Fig. 6. These measurements were taken at $100^{\circ} \mathrm{C}$ to reduce the relative influence of the leakage current from Shockley-Read-Hall recombination on the diode current in the forward region. From the $I-V$ characteristics in the reverse region, the diodes implanted at $7^{\circ}$ with a dose of $2 \times 10^{15} \mathrm{~cm}^{-2}$ suffer from high leakage, which can be attributed to the oxide recess at the edge of the contact hole, as presented in Figs. 2 and 4. A reduction of leakage is achieved by either increasing the implanted dose from $2 \times 10^{15} \mathrm{~cm}^{-2}$ to $3 \times 10^{15} \mathrm{~cm}^{-2}$ or by increasing the tilt angle from $7^{\circ}$ to $30^{\circ}$. Plausibly the increase to $30^{\circ}$ shifts the junction perimeter further underneath the isolation oxide, preventing exposure of the junction edge during the premetallization dip in $\mathrm{BHF}(1: 7)$. For implantation at $7^{\circ}$, increasing the

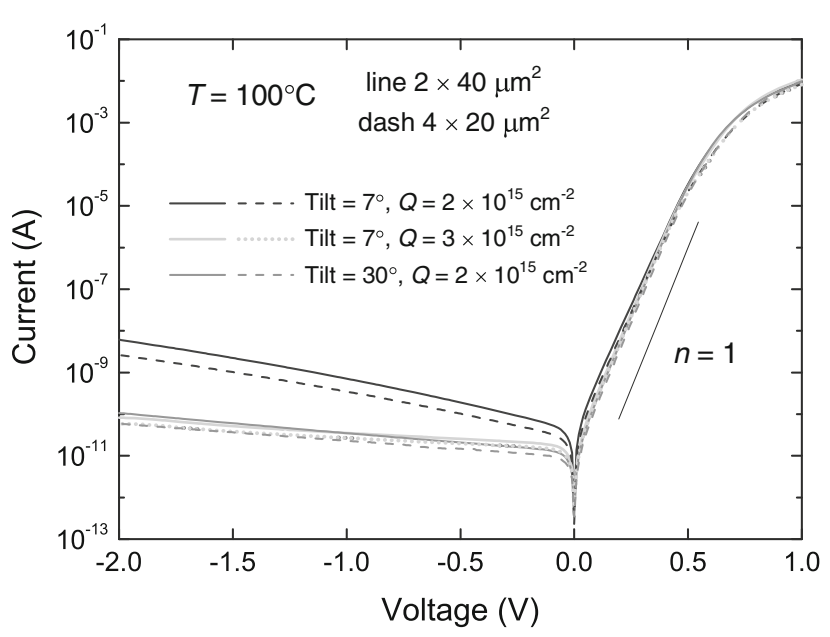

Fig. 6. Current-voltage characteristics of $n^{+} p$ diodes laser annealed at $1000 \mathrm{~mJ} / \mathrm{cm}^{2}$, for various implantation doses $Q$ and tilt angles.

dose can have the same effect, and moreover, the higher dopant concentration can also be more effective in limiting the spread of the depletion into the $n$-region. The energy transferred to the substrate by laser illumination melts the amorphized region, which then recrystallizes where the melt zone has extended to the amorphous-crystalline interface. At the perimeter of the diodes the heat transfer to the substrate may be larger than in the middle because the surrounding silicon mass that can absorb the heat is effectively larger. ${ }^{12}$ This would mean a less effective melting of the edge of the diode. Such an effect is probably the cause of the darker edge region seen in the TEM image of Fig. 7. These regions suggest that there might be some nonannealed point defects near the junction edges, and it is possible that these defects also contribute to higher leakage along the diode perimeter. ${ }^{18}$ This is substantiated by an area/perimeter analysis of diodes of different sizes. Typical characteristics are shown in Fig. 6 for diodes with sizes of $2 \mu \mathrm{m} \times 40 \mu \mathrm{m}$ and $4 \mu \mathrm{m} \times 20 \mu \mathrm{m}$, where the comparison shows that the latter diode with the smaller perimeter is less leaky. The metal acts as a sink for minority carrier (hole) injection that therefore increases as the junction becomes shallower. For junction depths below $20 \mathrm{~nm}$, this hole injection can become comparable to the electron injection into the substrate, and the total current, including the reverse current, increases. Moreover, the doping of the junction can become so low that it becomes completely depleted. 
This leads to punch-through phenomena that also will increase the current through the diode, and the reverse current can even be increased by decades. ${ }^{20}$ Such effects can prohibit the reduction of the leakage current to the low levels obtainable in conventional deep $n^{+} p$ junctions. Nevertheless, for junctions formed by implantation at $30^{\circ}$ tilt or with a dose of $3 \times 10^{15} \mathrm{~cm}^{-2}$ implanted at $7^{\circ}$ tilt, quite low leakage on the order of $7.5 \times 10^{-5} \mathrm{~A} / \mathrm{cm}^{2}$ at a temperature of $100^{\circ} \mathrm{C}$ and $1.9 \times 10^{-7} \mathrm{~A} / \mathrm{cm}^{2}$ at $25^{\circ} \mathrm{C}$ have been reached. An Arrhenius-type plot of the leakage currents measured over the temperature range of $25^{\circ} \mathrm{C}$ to $125^{\circ} \mathrm{C}$ in Fig. 8 confirms that at room temperature all types of analyzed diodes have an activation energy $\left(E_{\mathrm{a}}\right)$ close to half of the bandgap $\left(E_{\mathrm{g}} / 2\right)$, indicating a strong influence of generation-recombination currents. However, at elevated temperature, the $E_{\mathrm{a}}$ extracted for the diodes implanted at $30^{\circ}$ tilt or at $7^{\circ}$ with a higher implanted dose is larger due to a stronger influence of diffusion-type currents, and the diode behavior becomes closer to that of an ideal diode. Therefore, the analysis of the diodes in forward bias was also done at $100^{\circ} \mathrm{C}$.

When the diodes are forward biased, the influence of the residual defects can be identified as a deviation of the slope of the $I-V$ characteristics from that of an ideal diode with ideality factor $n=1$. The extracted values of $n$, as well as the reverse leakage current at $-2 \mathrm{~V}$ for the six diodes from Fig. 6 are summarized in Table III. The larger ideality factors correspond to the diodes with larger leakage in reverse region, and nearly ideal values are obtained for the diodes implanted at $7^{\circ}$ to a dose of $3 \times$ $10^{15} \mathrm{~cm}^{-2}$ or at $30^{\circ}$ and $2 \times 10^{15} \mathrm{~cm}^{-2}$. The area

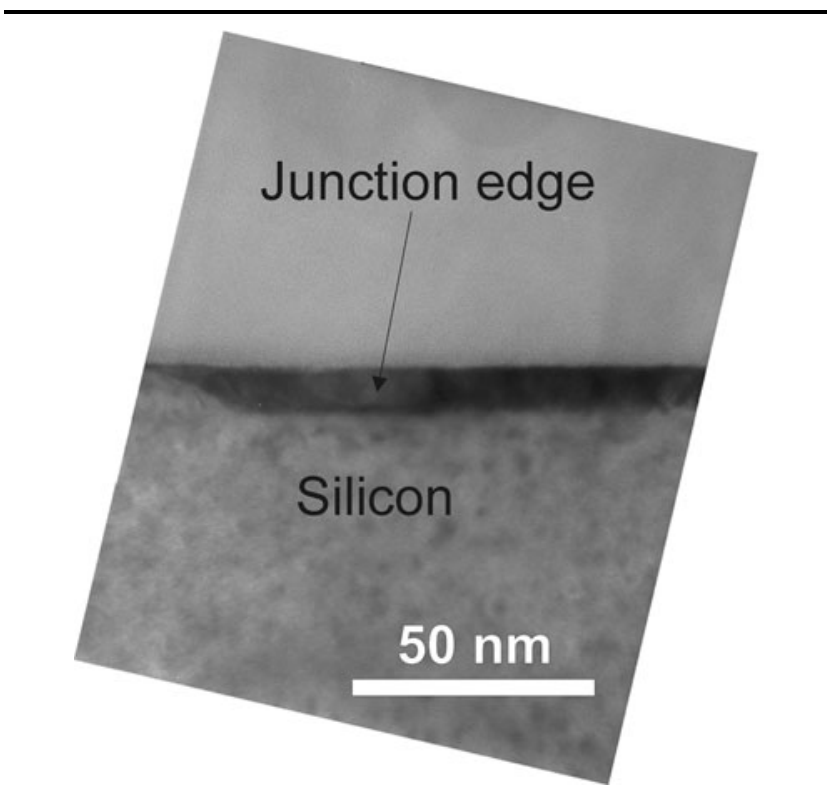

Fig. 7. TEM image of the edge of a fully processed junction implanted at $45^{\circ}$ and laser annealed at $1000 \mathrm{~mJ} / \mathrm{cm}^{2}$, with a dark region of $\mathrm{Si}$ near the edge of the contact opening that indicates incomplete epitaxial regrowth. component of the current at a forward bias of $0.3 \mathrm{~V}$ was extracted from the measurements of diodes with different dimensions, and the results are given in Table IV. As is evident from the extracted values, the largest area component of the current is achieved for the diode implanted at $30^{\circ}$ to a dose of $2 \times 10^{15} \mathrm{~cm}^{-2}$, which is the diode with the shallowest junction. With the scaling down of junction depth to the sub-20-nm range, the holes injected into the cathode from the $p$-substrate travel a very short distance before being recombined at the $\mathrm{Al} / \mathrm{Si}(1 \%)-\mathrm{Si}$ interface, which can result in a hole current that starts to become comparable to the current of electrons injected from the cathode. On the other hand, the electron current has little dependency on the junction depth, since the active doping level inside the $n^{+}$region is close to the maximum that can be achieved and a few $\mathrm{nm}$ change in the width of the micron-wide, lightly doped $p$-side of the junction will not have a significant impact on the electron current. In accordance, the high area component of the forward current confirms that the $30^{\circ}, 2 \times 10^{15} \mathrm{~cm}^{-2}$ junction is very shallow and has a hole current of the same order of magnitude as the electron current. The hole current can therefore not be neglected.

The possible improvement in leakage current and ideality factor obtained by increasing the implantation tilt angle was investigated further by fabricating diodes implanted with $\mathrm{As}^{+}$ions at $45^{\circ}$. However, the additional tilting of the ion beam led to a significant increase of the leakage current, which can be related to the extremely shallow junction, also under the oxide edge where interface states may then have more impact on the diode performance. As another possible enhancement of the process, it could be thought that a larger overlap of the junction with the oxide could be achieved by PECVD deposition after the laser annealing

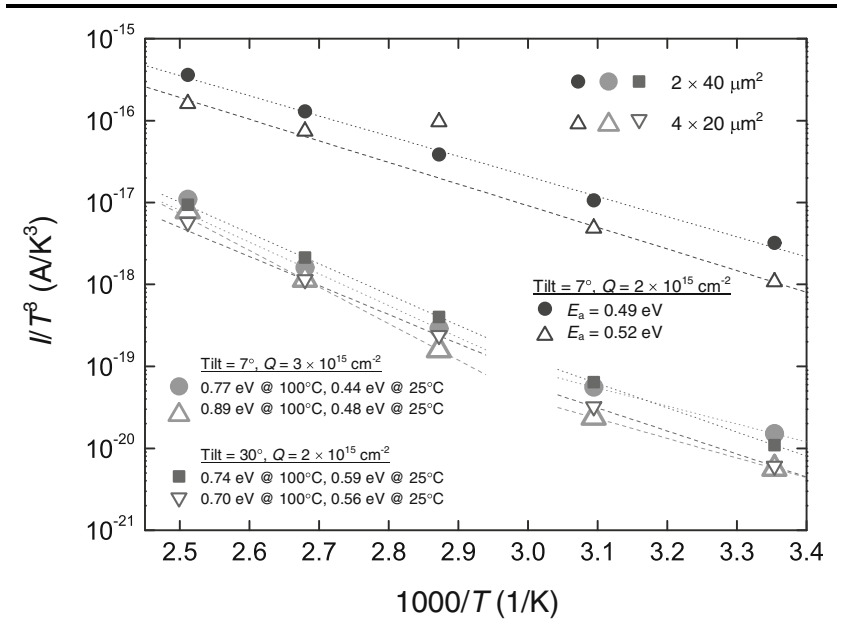

Fig. 8. Arrhenius plot of $I / T^{3}$ of $n^{+} p$ diodes laser annealed at $1000 \mathrm{~mJ} / \mathrm{cm}^{2}$, for various implantation doses $Q$ and tilt angles measured at reverse bias of $2 \mathrm{~V}$ and temperatures from $25^{\circ} \mathrm{C}$ to $125^{\circ} \mathrm{C}$. Activation energies $\left(E_{\mathrm{a}}\right)$ are extracted for each diode and are also listed in Table III. 
Table III. Ideality factors and activation energies extracted at $0.3 \mathrm{~V}$ and reverse leakage currents and activation energies extracted at $V=-2 \mathrm{~V}$ for the six diode measurements plotted in Fig. 6

\begin{tabular}{|c|c|c|c|c|c|c|}
\hline $\begin{array}{l}\text { Implantation } \\
\text { (Tilt Angle) }\end{array}$ & $\begin{array}{l}\text { Implantation } \\
\text { Dose }\left(\mathrm{cm}^{-2}\right)\end{array}$ & $\begin{array}{c}\text { Size } \\
\left(\mu \mathbf{m}^{2}\right)\end{array}$ & $\begin{array}{l}\text { Ideality } \\
\text { Factor }\end{array}$ & at $V=\stackrel{E_{\mathrm{a}}}{0.3 \mathrm{~V}(\mathrm{eV})}$ & $\begin{array}{c}\text { Reverse Current } \\
\text { at } V=-2 \mathrm{~V} \text { (A) }\end{array}$ & $E_{\mathrm{a}}$ at $V=-2 \mathrm{~V}(\mathrm{eV})$ \\
\hline \multirow[t]{2}{*}{$7^{\circ}$} & $2 \times 10^{15}$ & $2 \times 40$ & 1.13 & $0.56^{\mathrm{a}}$ & $6.2 \times 10^{-9}$ & $0.49^{\mathrm{a}}$ \\
\hline & & $4 \times 20$ & 1.12 & $0.55^{\mathrm{a}}$ & $2.7 \times 10^{-9}$ & $0.52^{\mathrm{a}}$ \\
\hline \multirow[t]{2}{*}{$7^{\circ}$} & $3 \times 10^{15}$ & $2 \times 40$ & 1.05 & $0.82^{b}$ & $8.3 \times 10^{-11}$ & $0.77^{\mathrm{b}}$ \\
\hline & & $4 \times 20$ & 1.04 & $0.83^{\mathrm{b}}$ & $5.9 \times 10^{-11}$ & $0.89^{b}$ \\
\hline \multirow[t]{2}{*}{$30^{\circ}$} & $2 \times 10^{15}$ & $2 \times 40$ & 1.04 & $0.80^{b}$ & $10.7 \times 10^{-11}$ & $0.74^{b}$ \\
\hline & & $4 \times 20$ & 1.04 & $0.80^{\mathrm{b}}$ & $5.9 \times 10^{-11}$ & $0.70^{\mathrm{b}}$ \\
\hline
\end{tabular}

The measurements used for extraction of ideality factors and leakage currents were performed at $100^{\circ} \mathrm{C}$. Activation energies are extracted from measurements in the temperature range between $25^{\circ} \mathrm{C}$ and $125^{\circ} \mathrm{C}^{\mathrm{a}}$ and between $75^{\circ} \mathrm{C}$ and $125^{\circ} \mathrm{C}^{\mathrm{b}}$

Table IV. Area component of the current extracted at $V=0.3 \mathrm{~V}$ at temperature of $100^{\circ} \mathrm{C}$

\begin{tabular}{|c|c|c|}
\hline $\begin{array}{l}\text { Implantation } \\
\text { (Tilt Angle) }\end{array}$ & $\begin{array}{l}\text { Implantation } \\
\text { Dose }\left(\mathrm{cm}^{-2}\right)\end{array}$ & $\begin{array}{c}\text { Area Component } \\
\text { at } \mathrm{V}=0.3 \mathrm{~V}\left(\mathrm{~A} / \mu \mathrm{m}^{2}\right)\end{array}$ \\
\hline $7^{\circ}$ & $2 \times 10^{15}$ & $2.90 \times 10^{-10}$ \\
\hline $7^{\circ}$ & $3 \times 10^{15}$ & $2.62 \times 10^{-10}$ \\
\hline $30^{\circ}$ & $2 \times 10^{15}$ & $8.96 \times 10^{-10}$ \\
\hline
\end{tabular}

followed by the opening of a smaller window to the junction, possibly by using inside spacers to reduce the contact window size. Nevertheless, experiments in this direction were not successful and resulted in a large spread in the $I-V$ characteristics with a high frequency of high leakage. Poor performance of the diodes processed in this way can be traced to the poor interface of the PECVD oxide to the laserannealed silicon, which cannot be passivated by the standard alloying in forming gas. A better interface to the PECVD oxide could improve the quality of diodes made in this way, and promising results have been obtained for the inductively coupled plasma (ICP) PECVD oxide deposited at $250^{\circ} \mathrm{C}$, which has a significantly lower concentration of interface states. $^{16}$

\section{Sheet Resistance}

Using van der Pauw structures, sheet resistance measurements were performed on the $n^{+}$ultrashallow laser-annealed junctions specified in Table II. The results as a function of laser anneal energy are plotted in Fig. 9. The increase in sheet resistance with higher tilt angles can be correlated to the reduction in implanted dose and junction depth that are determined from the SIMS measurements of Fig. 5. The influence of increasing the laser energy is to increase the level of dopant activation, which is connected to an improved degree of recrystallization of the region amorphized by ion implantation, thus lowering the sheet resistance. For laser energies above $1000 \mathrm{~mJ} / \mathrm{cm}^{2}$ some melting of the crystalline substrate also starts to occur,

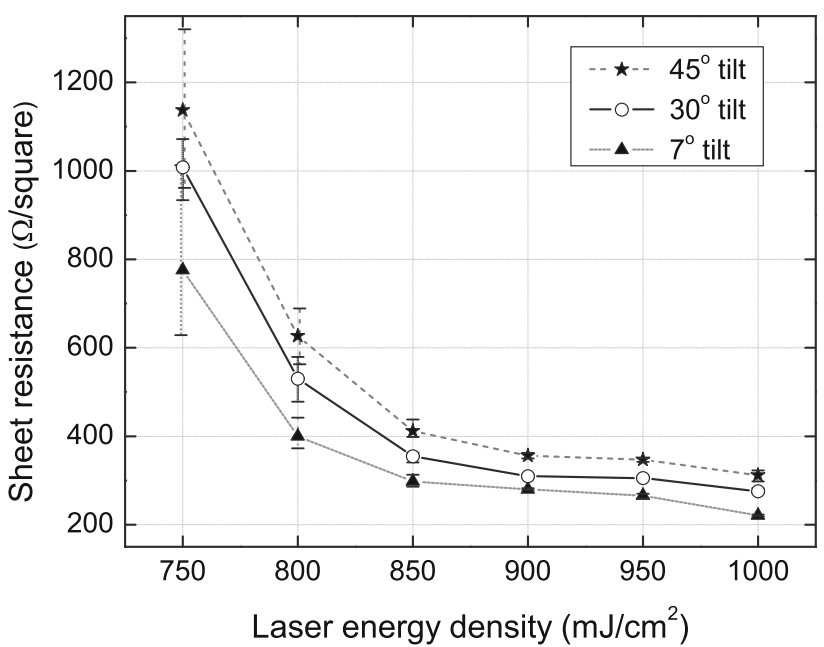

Fig. 9. Average sheet resistance over the wafer as a function of laser energy density of $n^{+} p$ diodes implanted with $5-\mathrm{keV} \mathrm{As}^{+}$to dose of $10^{15} \mathrm{~cm}^{-2}$ at different tilt angles. The vertical bars extend to the minimum and maximum measured value for each laser energy density and implantation angle.

driving the junction deeper. ${ }^{12}$ The optimum energy in our case is therefore in the range of $1000 \mathrm{~mJ} / \mathrm{cm}^{2}$ since the amorphous layer is then fully melted and recrystallized, while the LIPSS do not yet appear. Moreover, the spread in the sheet resistance values becomes smaller at higher energy densities. The minimum sheet resistances are obtained at the highest laser energy density investigated of $1000 \mathrm{~mJ} / \mathrm{cm}^{2}$; namely $220 \Omega /$ square, $275 \Omega /$ square, and $311 \Omega /$ square for $7^{\circ}, 30^{\circ}$, and $45^{\circ}$ tilt angles, respectively.

The junction depth predominantly depends on the depth of the region amorphized by implantation, and the decrease in vertical range achieved by increasing the tilt angle of the impinging ions is a suitable means of controlling the vertical dimensions of the junction, as seen in Table II. Moreover, the larger lateral overlap of the oxide isolation and the implanted region reduces the junction leakage caused by the enlargement of the contact opening during the premetallization removal of the native 
oxide in $\mathrm{HF}$ solution. On the other hand, if the sheet resistance needs to be minimized, then the deeper junctions implanted in a more vertical direction could be a better option. Attention must also be paid to the loss of the implantation dose from the reduction of the effective dose seen at the wafer surface, as well as the reflection of ions which are significant for the implantation at higher tilt angles.

Previous work has shown that the tilt angle of the implant can also have an impact on the residual defects after the implant/annealing in the regions in the vicinity of the implanted region. ${ }^{18}$ During implantation interstitials are injected into the substrate, and these are not completely annealed out at $400^{\circ} \mathrm{C}$, which is the maximum processing temperature used after ion implantation. The effects of this have been detected up to $0.6 \mu \mathrm{m}$ away from the implant itself, for example, as a reduced breakdown voltage in devices such as back-wafer-contacted varactors and bipolar transistors. ${ }^{21}$ When injected into boron-doped $p$-type silicon, the interstitials also cause a significant level of dopant deactivation ${ }^{22}$ that is readily detected by $C-V$ profiling, an example of which is shown in Fig. 10. The profiles of the active boron concentration after implantation (solid curves) show a strong dependence on the $\mathrm{As}^{+}$ implantation conditions. The boron deactivation increases with dose and decreases with increasing implant tilt. Therefore, using a $30^{\circ}$ tilt is also advantageous in situations where the background doping and defect density play a role in device performance.

\section{CONCLUSIONS}

A simple, low-temperature process flow for achieving good-quality ultrashallow $n^{+} p$ junction diodes has been demonstrated for $5-\mathrm{keV} \mathrm{As}^{+}$ implants activated by excimer laser annealing. Several generally applicable guidelines for achieving good diodes can be established on the basis of this work. With respect to the bulk, laterally uniform part of the diode away from the perimeter, it is important that the Si surface to be implanted is smooth and free of native oxide before implantation. The implant should be so shallow that the melt region encompasses the whole implanted region but deep enough to avoid laser-induced surface structuring effects on the Si surface that may affect the perfection of the underlying metallurgic junction region. Tilted implants can reduce the final junction depth of the $5-\mathrm{keV}$ implants to below $20 \mathrm{~nm}$. Moreover, they can also significantly reduce the number of interstitials sent deep into the substrate, which may otherwise cause background dopant deactivation and leakage currents.

With respect to the perimeter of the diode, the key to achieving good-quality diodes is the ability to terminate the metallurgic junction at an oxideto-silicon interface that is of good quality. In these

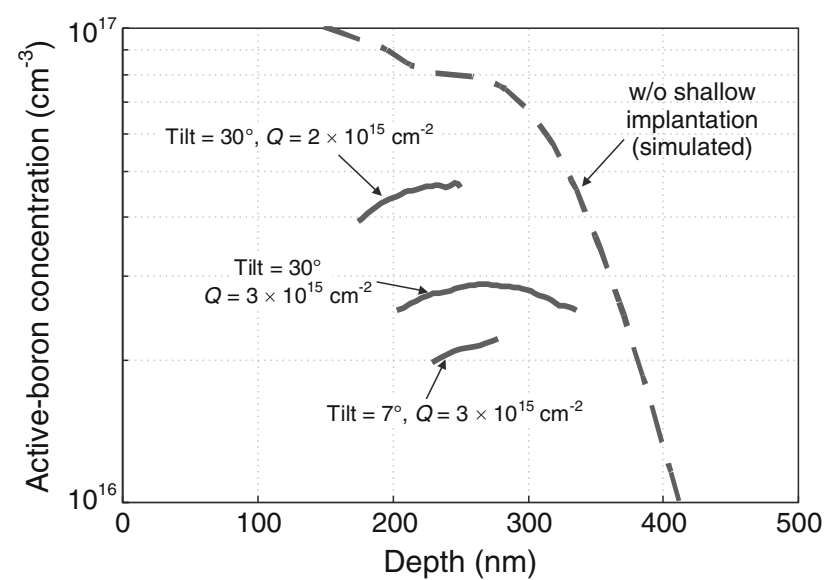

Fig. 10. $C-V$ doping profiles of the $p$-region of an $n^{+} p$ diode fabricated with a 5-keV $\mathrm{As}^{+}$implant at various tilt angles with different doses and laser annealed at $900 \mathrm{~mJ} / \mathrm{cm}^{2}$. The simulated $p$-profile before implantation is given by the dashed curve.

experiments this is achieved by using a thin layer of thermal oxide to cover the Si under a thicker lowtemperature isolation layer. After the growth of the isolation oxide, all processing steps are performed at temperatures below $400^{\circ} \mathrm{C}$. Here a 30 -nm-thin thermal oxide is applied, which is still sufficiently thick to avoid excessive widening of the contact window during the dip-etch used to remove native oxide before metallization. To localize the laser melting of the silicon to the desired diode region and particularly to protect the perimeter, a reflective mask of $\mathrm{Al}$ is applied. A thin layer of $\mathrm{Al}$ is used together with one-shot laser annealing to avoid problems with the post-laser-annealing $\mathrm{Al}$ morphology. Tilted implants increase the overlap of the oxide isolation with the diode perimeter, thus making the process more robust and reducing perimeter leakage. The completeness of the laser melt at the perimeter will depend on the thermal conductivity of the surroundings. In the present experiments, less melting of the perimeter with respect to the bulk is identified by TEM analysis, and this may be a source of extra perimeter leakage that should be taken into account when designing a specific process flow and diode structure.

The best results are achieved here with an implant of $2 \times 10^{15} \mathrm{~cm}^{-2}$ at tilt of $30^{\circ}$. For diodes with an area of $80 \mu \mathrm{m}^{2}$ this gives an ideality factor of 1.04 and reverse leakage at $-2 \mathrm{~V}$ in the range of $7.5 \times 10^{-5} \mathrm{~A} / \mathrm{cm}^{2}$ at $100^{\circ} \mathrm{C}$ and $1.9 \times 10^{-7} \mathrm{~A} / \mathrm{cm}^{2}$ at room temperature.

\section{ACKNOWLEDGEMENTS}

The authors wish to thank the staff of the DIMES IC-processing group for their assistance in device fabrication. This work has been supported by the EU FP6 project D-DotFET, the Philips/NXP PACD project, and the SmartMix MEMPHIS project. 


\section{OPEN ACCESS}

This article is distributed under the terms of the Creative Commons Attribution Noncommercial License which permits any noncommercial use, distribution, and reproduction in any medium, provided the original author(s) and source are credited.

\section{REFERENCES}

1. International Technology Roadmap for Semiconductors 2009, http://www.itrs.net, Accessed 23 November 2010.

2. B. Yu, Y. Wang, H. Wang, Q. Xiang, C. Riccobene, S. Talwar, and M.-R. Lin, International Electron Devices Meeting 1999 Technical Digest (1999), p. 509.

3. H.Y. Wong, H. Takeuchi, T.-J. King, M. Ameen, and A. Agarwal, IEEE Electron Device Lett. 26, 234 (2005).

4. A. Shima, H. Ashihara, A. Hiraiwa, T. Mine, and Y. Goto, IEEE Trans. Electron Devices 52, 1165 (2005).

5. C. Park, S.-D. Kim, Y. Wang, S. Talwar, and J.C.S. Woo, Symposium on VLSI Technology Digest of Technical Papers (2001), p. 69.

6. S. Baek, S. Heo, H. Choi, and H. Hwang, IEEE Electron Device Lett. 26, 157 (2005).

7. R. Surdeanu, Y.V. Ponomarev, R. Cerutti, B.J. Pawlak, C.J.J. Dachs, P.A. Stolk, M.A. Verheijen, M. Kaiser, M.J.P. Hopstaken, J.G.M. van Berkum, F. Rozenboom, L.K. Nanver, I. Hoflijk, and R. Lindsay, Proceedings of the 201st Electrochemical Society Meeting (2002), p. 413.

8. L.K. Nanver, J. Slabbekoorn, A. Burtsev, T.L.M. Scholtes, R. Surdeanu, F. Simon, H.-J. Kalhert, and J.W. Slotboom, Proceedings of the 203rd Electrochemical Society Meeting (2003), p. 119.

9. M.O. Thompson, G.J. Galvin, J.W. Mayer, P.S. Peercy, J.M. Poate, D.C. Jacobson, A.G. Cullis, and N.G. Chew, Phys. Rev. Lett. 52, 2360 (1984).
10. S. De Unamuno and E. Fogarassy, Appl. Surf. Sci. 36, 1(1989).

11. A. Matsuno, K. Kagawa, and Y. Niwatsukino, Proceedings of the 2nd International Semiconductor Technology Conference (2002), p. 148.

12. G. Fortunato, L. Mariucci, M. Stanizzi, V. Privitera, S. Whelan, C. Spinella, G. Mannino, M. Italia, C. Bongiorno, and A. Mittiga, Nucl. Instrum. Methods Phys. Res. B 186, 401 (2002).

13. V. Gonda, J. Slabbekoorn, and L.K. Nanver, 15th International Conference on Advanced Thermal Processing of Semiconductors RTP (2007), p. 257.

14. L.K. Nanver, N. Nenadović, V. d'Alessandro, H. Schellevis, H.W. van Zeijl, R. Dekker, D.B. de Mooij, V. Zieren, and J.W. Slotboom, IEEE Trans. Electron Devices 51, 42 (2004).

15. C. Biasotto, V. Jovanović, V. Gonda, J. van der Cingel, S. Milosavljević, and L.K. Nanver, International Conference on Ultimate Integration of Silicon (2009), p. 181.

16. V. Jovanović, C. Biasotto, L.K. Nanver, J. Moers, D. Grützmacher, J. Gerharz, G. Mussler, J. van der Cingel, J.J. Zhang, G. Bauer, O.G. Schmidt, and L. Miglio, IEEE Electron Device Lett. 31, 1083 (2010).

17. V. Gonda, A. Burtsev, T.L.M. Scholtes, and L.K. Nanver, 13th International Conference on Advanced Thermal Processing of Semiconductors RTP (2005), p. 93.

18. V. Gonda (PhD thesis, Delft University of Technology, Delft, 2008), p. 31.

19. A. Burtsev, H. Schut, L.K. Nanver, A. van Veen, J. Slabbekoorn, and T.L.M. Scholtes, Mater. Sci. Eng. B 114115, 109 (2004).

20. M. Popadić, G. Lorito, and L.K. Nanver, IEEE Trans. Electron Devices 56, 116 (2009).

21. L.K. Nanver, H. Schellevis, T.L.M. Scholtes, L. La Spina, G. Lorito, F. Sarubbi, V. Gonda, M. Popadić, K. Buisman, L.C.N. de Vreede, C. Huang, S. Milosavljević, and E.J.G. Goudena, IEEE J. Solid-State Circuits 44, 2322 (2009).

22. K. Kyllesbech Larsen, V. Privitera, S. Coffa, F. Priolo, S.U. Campisano, and A. Carnera, Phys. Rev. Lett. 76, 1493 (1996). 